\title{
A Half Century of Surgical Nutrition and Metabolism : History, Reflections, Perceptions, Controversies and Challenges
}

\section{Stanley J. Dudrick}

Saint Mary's Hospital, Waterbury, Connecticut, USA Professor Emeritus of Surgery, Yale University School of Medicine

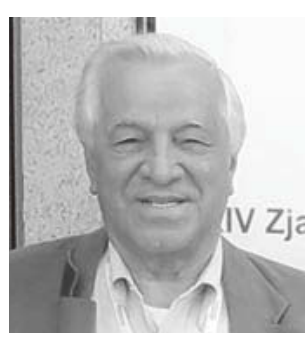

Some of the most significant events and discoveries prerequisite to the development of Total Parenteral Nutrition (TPN), starting in the early 17th century are presented and briefly discussed. A more detailed outline and discussion of the subsequent early contemporary highlights of the most relevant basic and clinical research; and the advances resulting in the first demonstration of the feasibility and practicality of TPN, and its successful, safe, and efficacious clinical applications almost five decades ago in the mid-twentieth century, are reviewed. An abridged discussion of the history, cause, and nature of early controversies which arose related to the development and clinical application of TPN is presented, together with the highlights of some of the more prominent controversies and challenges that continue to prevail, including the importance of maintenance of normal glycemia in critically ill patients, the judicious use of TPN versus Total Enteral Nutrition (TEN), and the nutritional support of geriatric patients, with and without cancer. Reflections related to nutritional support, especially in severely malnourished surgical patients ; TEN ; and TPN, together with some of the reasoning, insights, experiences, and philosophy of the author, and a compilation of many of the contributions and legacies of TPN to the modern practice of medicine which have occurred during the past 50 years, are presented.

Stanley J. Durick, M.D.

DATE OF BIRTH : $\quad$ April 9, 1935

PLACE OF BIRTH : $\quad$ Nanticoke, Pennsylvania

EDUCATION :

Nanticoke High School, Nanticoke, Pennsylvania, 1949-1953

Franklin and Marshall College, Lancaster, Pennsylvania, 1953-1957

University of Pennsylvania School of Medicine, Philadelphia, Pennsylvania, 1957-1961

\section{DEGREES :}

B.S., Biology Honors, Cum Laude, Franklin and Marshall College, 1957

M.D., University of Pennsylvania School of Medicine, 1961

Master of Arts (MA), Honoris Causa, Yale University, 1999

Doctor of Humane Letters (LHD), Honorary, Misericordia University, 2010

Doctor of Science (ScD), Honorary, Franklin and Marshall College, 2013

\section{INTERNSHIP :}

Hospital of the University of Pennsylvania (Rotating), July 1961-June 1962

\section{RESIDENCY :}

Assistant Resident in Surgery, Hospital of the University of Pennsylvania, July 1962-June 1966

Chief Resident in General Surgery, Hospital of the University of Pennsylvania, July 1966-June 1967 


\section{FELLOWSHIP :}

Research Fellow, Harrison Department of Surgical Research, University of Pennsylvania School of Medicine, July 1962-June, 1967

CERTIFICATION : $\quad$ American Board of Surgery, January 29, 1968, 15163

Certification Board for Nutrition Specialists, October 5, 200814030

CURRENT POSITIONS : Professor Emeritus of Surgery, Yale University School of Medicine, 2012-

Robert S. Anderson, MD, Endowed Professor and Medical Director, Physician Assistant Studies, College of Arts and Sciences, Misericordia University, 2011-

Clinical Professor (Adjunct Faculty), Department of Surgery, Temple University School of Medicine, 2012-

Clinical Professor of Surgery (Adjunct), Quinnipiac University, Hamden, CT, 1996-

Director Emeritus, Program in Surgery, Saint Mary's Hospital/Yale Affiliate, 2008-

Director Emeritus, Graduate Medical Education, Saint Mary’s Hospital/ Yale, 2008-

Chairman Emeritus, Department of Surgery, Saint Mary's Hospital/Yale Affiliate, 2007-

Consulting Surgeon, Saint Mary’s Hospital/Yale Affiliate, 2008-

Consulting Surgeon, Bridgeport Hospital/Yale-New Haven Health System, 2009-

Attending Surgeon, West Haven VA Hospital, 1998-2011 ; Consultant in Surgery, 2011-

Consulting Surgeon, Yale-New Haven Hospital, 2005-2011 ; Honorary Staff, $2011-$

Consulting Surgeon, Pennsylvania Hospital, Honorary Staff, 2012-

\section{BIOGRAPHICAL DIGEST}

\section{STANLEY J. DUDRICK, M.D., F.A.C.S.}

Stanley J. Dudrick, M.D. is widely recognized and respected throughout the scientific, academic and clinical world for his innovative and pioneering research in the development of the specialized central venous feeding technique known as intravenous hyperalimentation (IVH) or total parenteral nutrition (TPN). The basic investigative development and subsequent successful clinical application of this highly effective therapeutic modality has been described as one of the four most significant accomplishments in the history of the development of modern surgery, together with the discovery and development of asepsis and antisepsis, antibiotic therapy and anesthesia (JAMA 239 : 192, 1978). It has also been acknowledged as one of the three most important advancements in surgery during the past century along with open heart surgery and organ transplantation.

Born in Nanticoke, Pennsylvania, April 9, 1935, Dr. Dudrick received his B.S. in Biology with Honors in 1957 from Franklin and Marshall College in Lancaster, graduating Cum Laude. He was a member of Phi Beta Kappa honor fraternity and was awarded the Williamson Medal as the outstanding member of his graduating class. His M.D. degree was conferred by The University of Pennsylvania School of Medicine in 1961 followed by a rotating internship and residency training in General Surgery at the Hospital of the University of Pennsylvania where he served as Chief Resident in Surgery under Dr. Jonathan E. Rhoads until 1967. During this time, he also served concurrently as a Fellow in the Harrison Department of Surgical Research. After his training, he joined the faculty at Penn and ascended in rank from Instructor to Professor of Surgery at his alma mater within five years. In 1972, 
he was recruited to Houston as the first Professor and Founding Chairman of the Department of Surgery at the then new University of Texas Medical School at Houston and Chief of Surgical Services at Hermann Hospital/The University Hospital. Concurrently, he served as Professor of Surgery at the University of Texas System M.D. Andersen Hospital and Cancer Center. In 1988, he joined the staff of Pennsylvania Hospital, the nation's first hospital, in Philadelphia as Chairman of the Department of Surgery, Surgeon to the Hospital, Director of the Residency Training Program in General Surgery and Clinical Professor of Surgery at the University of Pennsylvania. On May 1, 1990, he was appointed Surgeon-in-Chief of the Center for Cardiovascular Disease and Director of the Hermann Nutrition and Human Performance Center, the Nutritional Support Service, and the Nutritional Science Center at Hermann Hospital and Clinical Professor of Surgery at the University of Texas Medical School at Houston.

In November, 1994, he began serving as Associate Chairman of the Department of Surgery and Director of the Program in Surgery at Saint Mary's Hospital, a Yale Affiliated Teaching Hospital, in Waterbury, Connecticut and as Professor of Surgery at Yale University School of Medicine. In October, 1995, he assumed the additional responsibilities at Saint Mary's Hospital as Director of Graduate Medical Education. In October, 1996, he was also appointed Adjunct Clinical Professor of Surgery on the faculty of Quinnipiac College. Yale University granted him a Master of Arts Honoris Causa Degree in 1999. Between January, 2000 and September, 2002, he served additionally as Chairman of the Department of Surgery and Director of Surgical Education for the newly integrated Bridgeport Hospital/Yale New Haven Health System. He then returned to serve as Chairman of the Department of Surgery, Director of the Training Program in Surgery and Designated Institutional Official for Graduate Medical Education at Saint Mary's Hospital/Yale Affiliate in Waterbury, Connecticut, while continuing to serve as Professor of Surgery at Yale University School of Medicine. Dr. Dudrick assumed his current Chairman-Emeritus, Department of Surgery, status in October, 2007, while continuing as Director of the Training Program in Surgery until July, 2008, when he became Director-Emeritus of the Program in Surgery at Saint Mary's Hospital. He currently continues to be active in both of these positions at Saint Mary's Hospital and as Professor of Surgery at Yale. Additionally, he serves as a consultant to the newly established Training Program in General Surgery at Danbury Hospital. In January, 2011, he also joined the Faculty of Misericordia University in the newly established Physician Assistant Studies Department of the College of Arts and Sciences, as the first occupant of the Robert S. Anderson, M.D. Endowed Chair, Professor, and Medical Director of the emerging Physician Assistant Studies Program.

A prolific medical writer, Dr. Dudrick was acknowledged by Current Contents, a publication of the Institute for Scientific Information, as the author or co-author of 2,535 scientific reference citations during a 13 year period, the most for any general surgeon in the literature of that time. His more than 800 published works include a wide variety of topics on the care and management of surgical patients, especially those with complex nutritional, metabolic, critical care and re-operative problems.

Since 1974, he has served on more than fifteen Editorial Boards of scientific journals and professional publications including the prestigious Annals of Surgery. Of the several books he has produced, he is most proud of having served as a Co-Editor of the American College of Surgeons Manual of Surgical Nutrition, and as the Editor of the Manual of Preoperative and Postoperative Care, The Surgical Clinics of North America-Current Strategies in Surgical Nutrition, The Biology and Practice of Current Nutritional Support, and the Surgical Clinics of North America-Nutrition and Metabolism of the Surgical Patient, Part I and Part II.

Dr. Dudrick is a Fellow of the American College of Surgeons, was elected a Director of the American College of Surgeons South Texas Chapter and served as a Governor at Large of the American College of Surgeons from the State of Texas from 1979-1985. The Board of Regents selected him as the recipient of the prestigious American College of Surgeons Jacobson Innovation Award in 2005. In 2008, he received the Distinguished Service Award of the American College of Surgeons Connecticut Chapter. 
Certified by the American Board of Surgery, he served this prestigious organization as an Examiner continuously since 1974, as a member of its Board of Directors and then, as a Senior Member of the Board for a total of 26 years. The Certification Board of Nutritional Specialists has also honored him as a Certified Nutritional Specialist ; as member of its Board ; and as a Vice Chairman and active member of several committees. He is a fellow of the American College of Nutrition and has served on its Twenty-First Century Board of Directors. Among the more than 125 honors and awards which Dr. Dudrick has received are the AMA Joseph B. Goldberger Award in Clinical Nutrition ; the AMA Brookdale Award in Medicine ; the Seale Harris Medal of the Southern Medical Association ; the Ladd Medal of the American Academy of Pediatrics ; the American College of Nutrition Goldsmith Award ; the Distinguished Alumnus Citation, the Alumni Medal, and The President's Medal of Franklin and Marshall College ; and the American Surgical Association's First Flance/Karl Award which was shared with Dr. J. E. Rhoads in 1997 for seminal and lifetime scientific contributions to surgery. In 2009, he received the American Surgical Association Medallion for Scientific Achievement for Distinguished Service to Surgery, the highest honor bestowed by the American Surgical Association. In February, 2011, he was honored with the Legends of Neonatology Award by NEO, The Conference for Neonatology. In June, 2011, he served as The Gross Lecturer and Visiting Professor in the Department of Pediatric Surgery, Children's Hospital Boston and Harvard Medical School. In September, 2011, he received the Nathan Smith Award, for Distinguished Service to Surgery, from the New England Surgical Society.

He holds membership in more than 100 academic, honorary, professional medical and scientific societies, and has given hundreds of invited lectures throughout the world. He is a Founding Member of the Association for Academic Surgery, the Association of Veterans Administration Surgeons, the American Trauma Society, the International Society for Parenteral Nutrition and the American Society for Parenteral and Enteral Nutrition. He is also a member of Alpha Omega Alpha Honor Medical Society, the Phi Beta Kappa Associates, and Sigma Xi Scientific Research Society. He has served as President of the International Society for Parenteral Nutrition, was the first President of the American Society for Parenteral and Enteral Nutrition, Chairman of the Surgery Section of the Southern Medical Association and President of the American Society of Nutritional Support Services. He has been a member of the Board of Trustees of Franklin and Marshall College for 25 years from 1985 to 2010, serving as Vice Chairman for eight years. He was elected Trustee Emeritus in 2010. He also served as Chairman of the National Alumni Council of the University of Pennsylvania School of Medicine and received the University of Pennsylvania Medical Center Alumni Service Award. He was voted the Distinguished Graduate Award by the Faculty of the School of Medicine of the University of Pennsylvania in 2007 ; and serves as a member of the Alumni Advisory Board. He served as Chairman of the 50th Reunion of the Class of 1961, and addressed the Graduating Class of 2011 of the University of Pennsylvania School of Medicine at their Graduation Ceremony in May, 2011. He is listed in Who's Who in the South and Southwest, Who's Who in America, International Who's Who in Medicine and Healthcare, Who's Who in Science and Engineering, Who's Who in American Education, Who's Who in the East, and Who's Who in the World. He has served on the Board of Directors of the Waterbury Symphony Orchestra for 11 years since 1999 ; in 2010 he was elected Director Emeritus. He remains active as a member of the Waterbury Medical Society and the University Club of Waterbury. He serves as Chairman of the Saunders Foundation for the Sick and Infirm of the Borough of Naugatuck since 2009, and as Medical Director of Emergency Medical Services of the Borough of Naugatuck since 2012.

He has been elected to eighteen honorary memberships and fellowships, including Honorary Fellowship in the Philippine College of Surgeons ; the American Pediatric Surgical Association ; the American Academy of Pediatrics ; the College of Medicine and Surgery of the Republic of Costa Rica; and the Societies for Parenteral and Enteral Nutrition of Brazil, Venezuela, Mexico, Colombia, Latin America, Japan, Poland and the Czech Republic. He received the Association of Mexican Surgeons Lifetime Achievement Award in 2005. He was elected to Honorary Fellowships in the Polish Surgical Society in 2005 and to the Association of Colombian Surgeons in 2006. The National Academy of Medicine of Colombia elected him an Honorary Member in 2006 ; the Mexican Academy of Surgery 
elected him an Honorary Academic Member in 2008 ; and the Bohemian Medical Association of the Czech Republic granted him Honorary Membership in 2008. In May, 2010, he was invested by Misericordia University with the Honorary Degree of Doctor of Humane Letters for his extraordinary contributions to Surgery and Nutrition. In May, 2012, a new, modern hospital in Skawina (Krakow suburb), Poland was formally dedicated and named the Stanley Dudrick Hospital in his honor and to acknowledge his world-renowned contributions to surgery, nutrition, and the care of critically ill patients. The Stanley J. Dudrick Annual Lecture was established "To honor Dr. Dudrick as an outstanding educator and founding Chairman of the Department of Surgery, 1972-1980," and "recognizing his contributions to the education of the Surgical Residents at the UT Medical School at Houston" by The UT Surgery "Dudrick-Moody-Andrassy" Alumni Society, and The University of Texas Health Science Center at Houston honored him with their highest award, The UTHSCH Medal for "Excellence in Research, Education, Clinical Care," Houston, Texas, April, 2013. Franklin and Marshall College awarded him the Honorary Degree, Doctor of Science (ScD), in May, 2013.

In 1981, his former residents, fellows and associates formed the Stanley J. Dudrick Surgical Foundation and Society, and in 2013, established the Annual Stanley J. Dudrick, MD, Lecture Series at the University of Texas School of Medicine at Houston in his honor as the Founding Professor and Chairman of the Department of Surgery. In 1985, the American Society for Parenteral and Enteral Nutrition established the Stanley J. Dudrick Research Scholar Award, a \$5,000 annual award granted in his honor to young investigators in recognition of their past research accomplishments and future research potential. In 2003, his former residents and fellows, colleagues, patients and friends established the Stanley J. Dudrick Research and Education Fund in the Department of Surgery at Saint Mary's Hospital, Waterbury, Connecticut. He has received multiple teaching awards from his students and residents throughout his tenure at the University of Pennsylvania School of Medicine, The University of Texas Medical School at Houston, Saint Mary's Hospital/Yale Affiliate, and the Yale University School of Medicine. In 2009, Saint Mary's Hospital/Yale Affiliate dedicated The Stanley J. Dudrick, $\mathrm{MD}$, Department of Surgery in his honor.

His investigative endeavors have recently been focused primarily on the nutritional and biochemical manipulations of amino acid, carbohydrate, fat and micronutrient metabolism and their interrelationships with nutritional status, optimal human cellular, cognitive, and physical performance ; fitness ; preventive medicine ; generation and regression of atherosclerosis ; and outcomes in geriatric and cancer patients, and in other critically ill patients.

Dr. Dudrick and his wife Theresa reside in Naugatuck, Connecticut and Eaton Center, New Hampshire and are the proud parents of two sons and four daughters and the delighted grandparents of ten granddaughters and six grandsons. 